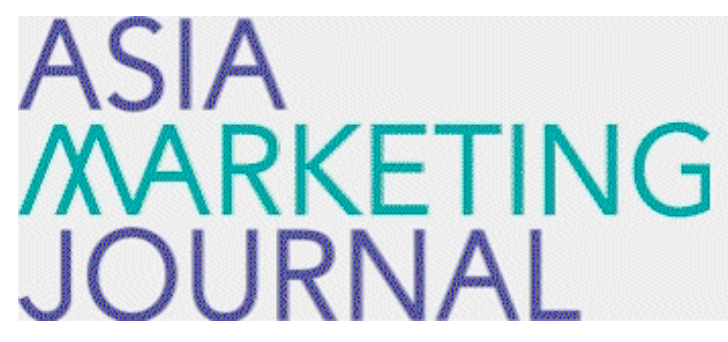

ASIA MARKETING JOURNAL

Volume 15 | Issue 2

Article 7

7-30-2013

\title{
What makes Consumers to Prolong their Consumption on Perishable Food beyond Its Expiration Date?
}

Hyun Suk Suh

Hyoung Jun Ju

Follow this and additional works at: https://amj.kma.re.kr/journal

Part of the Marketing Commons

\section{Recommended Citation}

Suh, Hyun Suk and Ju, Hyoung Jun (2013) "What makes Consumers to Prolong their Consumption on Perishable Food beyond Its Expiration Date?," Asia Marketing Journal: Vol. 15 : Iss. 2 , Article 7.

Available at: https://doi.org/10.53728/2765-6500.1522

This Article is brought to you for free and open access by Asia Marketing Journal. It has been accepted for inclusion in Asia Marketing Journal by an authorized editor of Asia Marketing Journal. 


\title{
What makes Consumers to Prolong their Consumption on Perishable Food beyond Its Expiration Date?
}

\author{
Hyunsuk Suh* \\ Hyoungjun $\mathrm{Ju}^{* *}$
}

Consumers empty perfectly safe to intake perishable foods everyday if they are older than what prints on expiration date. The variation in expiration dating is freshness labeling represented in various terms such as sell by, package, best before, and so on. Regardless of the terms used and meanings are attached, consumers tend to conceive of freshness labeling on food as end of its shelf-life. Consequently, the food waste becomes a big issue for businesses in food sector. In an effort to demonstrate flexibility on this, KFDA(Korea Food \& Drug Administration) introduced "best before" date in domestic market place to reduce food waste, based on the food safety test conducted by KCA(Korea Consumer Agency 2009). The results indicated freshness labeling on food should not be considered as the end of its life. Current study examined the underlying mechanisms(i.e. risk perception, self-construals, and indecisiveness) that influence consumers' intention on prolonged consumption of food beyond its stamped date when the KCA test results are shown to them. In addition, the moderating effect of regulatory focus is tested in the causal relationships between underlying mechanisms and different groups of prolonged consumption intention. Study participants are divided into three groups of prolonged consumption intention: no-change, moderate-change, and wide-change. The group with moderate-change in intention being as our point of reference, logistic regression analyses are conducted on 276 sample population. The results indicated that consumers with high source credibility risk are likely to show wide-change in intention on prolonged consumption while physical risk did not show significance. The consumers with independent self-construal are likely to show no-change in intention on prolonged consumption while interdependent self-construal did not show significance. Indecisiveness showed association a group with wide-change in intention on prolonged consumption. The moderating effect of regulatory focus showed valid results in most situations: the promotion-focused consumers showed wide-change in intention, while prevention-focused consumers showed no-change in intention. Furthermore, the moderating effect of promotion-focus showed a dominant position over the causal effect of indecisiveness in which decisive consumers(i.e. no-change in intention): if they are promotion-focused they tend show for the wide-change in intention instead. It is important to note

\footnotetext{
* Associate Professor, College of Business and Economics, Chung-Ang University(hssuh@cau,ac.kr), corresponding author

** Ph,D Candidate, College of Business Administration, Chung-Ang University(jun4335@naver.com)
} 
that for those promotion-focused consumers(or situations), promotion-related arguments are more effective, while for those prevention-focused consumers(or situations) prevention- related arguments are more effective means of persuasion.

Key words: risk perception, self-construal, indecisiveness, regulatory focus

\section{Introduction}

All food products are given expiry dates to guarantee quality towards consumers. This is especially important for food products whose freshness do not last for a long time. For instance, in preparation of a cheese omelet, if the cartoon of egg is printed, "EXPFEB10": the Cheddar is stamped with "Used by Feb 19": the milk is dated as "Sell by Feb 27." It's March 5. Can you safely scramble, or should you switch to a loaf of bread and cream cheese which says "Best Before June 11"? Concerns with food safety have led producing companies to put expiry dates on the package of product obligatorily. A recent variation in expiration dating is freshness labeling, such as "used by" or "best before" dates and often, they are conceived by consumers as the last date to guarantee a food quality. However, this appears to be done not only for food safety reasons for quality assurance but also for marketing reasons(Wansink 2005: Wansink and Cheney 2005). Useful as they may be, freshness dates are only helpful if consumers know what they mean in terms of purchase and home storage. Consumers throw perfectly good food down the drain because they fail to understand that some forms of dating allow time for home storage before the product begins to decline. A small change in freshness of food is difficult for most people to assess(Cardello and Schutz 2003). The food quality is typically measured using objective indices such as nutrition, and microbiological characteristics of food. For example, a common practice for setting expiry date for pork product is at $\mathrm{p}+7$ (7 days after production) at a maximum temperature of 4 degrees Celsius. On a regular basis, a part of production batch is checked whether the total number of microbes is below a maximum accepted level, which is Log $7.0 \mathrm{CFU} / \mathrm{cm}^{2}$. It is selected as the endpoint of shelf life because above this level, the bacteria begin to spoil from the surface of a meat(Knox et al. 2008). However, evaluations on food quality are consumer-based, which are subject to individual expectations and perceptions. It means that consumers' final evaluation lies somewhere between where it would be without objective information and where it would be with such information(Cardello et al. 2000: Mela 
1999: Rozin and Tuorila 1993). Wansink and Park(2002), in their food evaluation research found that peoples' prior expectations before consuming a food serve to anchor their posterior evaluation. If they know what to expect, they tend to be hypersensitive to these cues and become overly influenced by them. For such a reason, it is expected that freshness labeling influences on consumers' evaluation of food quality more than the actual condition of the food. A consumer's view on food quality may be more of binary: people may think of foods as either fresh or not fresh. Therefore the freshness labeling significantly acts as a point of reference on consumers judgment on food whether it is fresh or stale. This implies that the difference between 30 days prior to and 10 days prior to expiration date would bring less significant perception on the judgment of "freshness" compare to, between 1 day prior to and 1 day after the expiration date.

In reality, consumers empty perfectly safe to intake foods such as premium meats, fresh baked goods, and dairy products into the trash every day when they age longer than what prints on the 'freshness labeling.' Because consumers tend to think the freshness labeling indicates the end of its shelf-life: they are fearful of eating something past its stamped date and take it as gospel rather than a guideline, as if a carton of milk will turn to poison at the stroke of midnight on the date named on its label. Consequently, the food waste becomes a big issue for businesses in the food sector. In an effort to demonstrate flexibility on this, a variety of terms in 'freshness labeling' are offered in the market place. "Use by" or "best if used by" date is referred as the last date the product is likely to be at peak flavor and quality. It doesn't mean that food is unsafe after that date. However, the food is practically unmarketable after the date is passed. "Sell by" date indicates the last day which a product should be sold. It takes into account time for the food to be stored and used at home. Consumers have to purchase the product prior to the date, but consumption need not occur by then. However, the date instructs store personnel when to remove the product from the shelves, for mark down or disposal, depending on the freshness condition of food. "Pack" or "package" date reveals the day of manufacture, processing or packaging, not whether the food is too old to trust. Consumers can tell which package is fresher and reflect on their choice decision on purchases. A pack date isn't an indication of safety. "Expiration" date indicates the last date on which they should be eaten or used. It marks either the end of a product's full usefulness or the end of a product's full nutritional value. Eggs are an exception. Expiration date on eggs really means sell by date, in which next 3 to 5 weeks past expiration date is still safe to consume. "Best before" or "minimum durability" date indicates number of periods which consumer's expectation on food quality 
is guaranteed when kept at recommended conditions(i.e. temperature and or required methods) (Korea Consumer Agency(KCA) 2009: Codex). Different countries adopt these terms differently. For instance, Japan practices "use by," and "best before" dates, while US adopts "use by," "sell by," "best if used by," and "packaging" dates. In domestic marketplace, the "best before" date has been introduced in 2007 when "sell by" date alone was practiced before then(eggs and a specific milk brand also use "package date" for both safety and marketing reasons). However, most of domestic food manufactures still practice sell by date only. Those with expired sell by date are prohibited by the law for circulation and sale(KCA 2009).

KFDA(Korea Food \& Drug Administration) introduced "best before" date to domestic marketplace in an effort to cut down on food wastes and public awareness on the freshness labeling. However, still many consumers are found to throw away fresh to consume food products when they get older than the date printed on their freshness labeling. KCA(2009) reported daily disposed of food garbage from family homes is 7.415 tons which requires more than 12 trillion won to process them annually. If $1 \%$ of food garbage can be reduced from each home, it will add up to 121.7 billion won savings annually. Of all products, perishables such as milk, milk products, fish, meat, poultry, and some baked goods have relatively short shelf life, and must be kept under refrigeration otherwise they easily play host to bacteria, yeast, molds: or enzymes break down to foster offflavors and decay. The Office of Technology Assessment(OTA), an office of United States congress which practices and encourages delivery of public services, specifically defined milk and milk products as easily spoiled, and only short time storable food category. Milk and milk products which have passed their sell by dates are tested on their $\mathrm{pH}$ level, and bacterial counting(along with the number of colon bacillus) by the center for food microbiology which is a subdivision under KCA. The results indicated that milk, when kept in refrigeration, still retains low level of $\mathrm{pH}$ level(6.54 6.88) which indicates perfectly fresh condition up to 50 days past its sell by date. Even when they are kept in package-opened condition, if properly refrigerated, the level of $\mathrm{pH}$ is maintained between 6.59 and 6.85 which are still safe to consume. In the test for bacterial counting, including with the number of colon bacillus, none of them was found after 50 days have passed for both sealed and package-opened products. For cheese product, up to 70 days past sell by date was safe to consume with no signs of bacterial presence. All tested products were kept between $0 \sim 5$ degrees Celsius during the whole testing period. It was evidenced that the proper temperature(i.e. between $0 \sim 5$ degrees Celsius) is the most significant factor for food quality and if such condition can be maintained, food consumption is safe even after 50 days 
have passed its sell by date. These extra dates to safely consume milk and milk products following the "sell by" date are reflected on "best before" date, in an effort to prolong their consumption, thereby cut down on food waste by KCA. Despite the fact that "sell by" date does not indicate the last day to safely consume food product, still many consumers fail to understand what the term implies correctly, thereby refuse to consume the one which passed its stamped date. This makes perfectly safe to consume food products go down to the trash.

As stated above, there is an ambiguity about the usage of what consumers often refer to as "expiration dates." In an effort to understand the role of "best before" date on consumers who basically conceive all types of freshness labeling as the last day(i.e. deadline) to consume the product, the current study attempts to investigate two questions: (1) What underlying motives or mechanisms influence consumers to prolong their consumption intention of perishable food product beyond its freshness labeling, when KCA test results on extra dates to 'safely intake foods' beyond stamped dates are presented to them. In addition. (2) the influence of individual's 'goal-achieving' strategic intentions will be explored in the causal association between personal characteristics and groups of consumers with different intentions on prolonged consumption, to see how they make an impact on the given relationships. To do that, a set of hypotheses will be developed to em- pirically test through a survey of consumers' perceptions and intentions with respect to the following important perishable food, milk. The milk being selected as an object of our study because it is most widely and frequently consumed perishable(Mitsostergios and Skiadas 1994). This product is easier for consumers to conceptualize due to its package, size, and labeling are quite standardized compared to other perishables and even in comparison with other milk products.

In the survey, two rounds of consumers' intention on prolonged consumption of milk beyond its stamped date, will be measured: one prior to(one's true intention), and one after KCA test results being shown(changed intention). The difference in dates between initial measurement(i.e. pre-KCA result being shown) and one after exposure to KCA result (i.e. post-KCA result being shown) is calculated for each respondent, to divide them into different groups of intentions. Possibly, three different groups can turn up: one with zero difference in date change(a group with unchanged intention), one with moderate date changes(a group with moderate change in intention), and one with wide date changes(a group with drastic change of intention). It is assumed that a group with negative date changes that is, reduced number of days on their intentions for consumption of milk, after they have been exposed to KCA test result, will not likely to occur. Therefore these three groups are ex- 
pected to collectively exhaust our entire study population. Then, the association between various personal motives and these different groups will be explored. To do this, a standard of comparison of a group needs to be chosen. This study sets a group of 'moderate change in intention' as the reference point to make comparisons with remaining groups: no change, and wide change in intention (hereinafter, a group with unchanged intention refers to as 'no-change group' while a group with moderate change in intention refers to moderate-change group', and a group with wide change in intention refers to "wide-change group'). This is because when consumers are exposed to reliable source of information, a certain degree of behavioral change in compliance to the information is expected to occur in most cases. And that "certain degree" of change is well represented in 'moderate-change group' of our study. This means, individuals in moderate-change group are expected to make appearances naturally. Since understanding the underlying mechanisms on groups showing rather "unnatural" behaviors is more significant to explore, thereby becomes the goal of the study, and setting what conceived as a normal group as the point of reference to make comparisons with other groups to see how they deviate from the norm, is the primary focus of the current research.

\section{Theory and Hypotheses}

A small set of research attempts to understand how consumers incorporate freshness labeling into their purchase decisions (Cardello and Schutz 2003: Harcar and Karakaya 2005: Wang et al. 2008). Cardello and Schutz(2003) in their study of the importance of food freshness in purchasing decision on consumers, found "freshness" is ranked below tasted and nutrition, and is as important as price. Not surprisingly, a majority of North American consumers reported checking freshness dates prior to purchase, and few $(7-15 \%)$ are willing to consume the product beyond its freshness date(Harcar and Karakaya 2005). The freshness and safety are also important for Chinese consumers on supermarket sold perishable products. According to Wang et al. (2008), from their survey of Beijing consumers nearly all respondents were willing to pay a price premium for HACCP(Hazard Analysis Critical Control Point)-certified milk products. In reality, milk products with HACCP labels in Beijing supermarkets sold at a price premium of about $5 \%$ over products without such labels at the time. These studies implicate consumers do appear to value, search for, and use such information of 'freshness' and or 'safety' in making purchase decisions on perishable foods, such as milk and milk products. Most importantly, consumers' perceptions on quality risk of perishable foods play a key psychological determi- 
nant of their consumption behavior. This is because perishable foods have a relatively short shelf life, in which their quality decreases until they eventually spoil and decay compare to other kinds of products such as fashion or computers products(the quality on these items also are deteriorated and outdated, but with much longer shelf life). Because grocery store perishables decay over time and reaches to a point when they can no longer be sold, managers must understand consumers' willingness to consume across the shelf life to be able to sell them before they go bad.

Much of the research on perishable goods has come from the operations research literature and has focused on inventory and return policy (Hahn et al. 2004), optimizing pricing(Abad 2003: Li 2001), and ordering and restocking policies(Chun 2003: Fujiwara et al. 1997). Although the management of perishable goods such as fresh meat, poultry, and dairy depends on many of the factors suggested in these studies such as seasonality, inventory, and buyback deals, an understanding of consumers awareness of, perceptions of, and behavior with respect to 'freshness dates' is not presented. Our study is different from those previous studies in that we explicitly focus on consumers' perception and behaviors on their "willingness to consume" on specific grocery store perishable good(i.e. milk), longer than what says on freshness labeling when 'safety' cue(i.e. KCA information) is provided to them. Therefore, this study provides the unique work to $\mathrm{ex}^{-}$ clusively investigate consumers' awareness of freshness dates, their influence on willingness to prolonged consumption on milk as it ages beyond freshness labeling, and the influence of safety cue provided by KCA on this mechanism of "willingness for prolonged consumption," In terms of doing so, the influence of consumer characteristic factors and perceptions on given situation should be explored to have better understanding on their decision outcomes(i.e. nochange, moderate-change, or wide-change in their prolonged consumption intention). Perceived risk is one of the factors in our consideration set that is assumed to influence on consumers decision outcomes in this study.

Perishable food scares such as salmonella in eggs, milk, and poultry, and listeria in cheese products have caused health concerns among consumers and have brought changes in their purchase behaviors(Mitchell 1998). These scares caused retail sales of perishable products to drop, consumers to confirm freshness labeling prior to purchase, and to follow safety precautions in their consumption process(Yeung and Morris 2001). Therefore, the main factor driving the behavior of consumers in such situation is the perceived risk associated with purchasing and consuming what may be "unhealthy" perishable food products. This study particularly focuses on the latter part, thereby the "perceived risk" we are looking for here, is associated with consumption of what may be unhealthy per- 
ishable food.

Since the influence of safety cue provided by $\mathrm{KCA}$ in the mechanism of "willingness for prolonged consumption" is primary focus of our study, we are curious what consumer characteristic factors on the given situation(i.e. exposure to $\mathrm{KCA}$ test result) will bring about different decision outcomes(i.e. no-change, moderate-change, or wide-change in their prolonged consumption intention). Along with risk perception factor, we have decided to look into personal factors of self-construal and indecisiveness. The selfconstrual deals with an individual's perceptions, evaluations, and behaviors(Markus and Kitayama 1994: Triandis 1989), the focus is to see whether consumers think, feel, and act in relationship with external influencers such as what others say, and information being exposed to. Persons with strong independent self-construal can show disconnected reactions to external influencers because primary components of the independent self-construal are unique in personal traits, abilities, preferences, interests, goals, and experiences. Persons with independent selfconstrual tend to maintain a sense of 'autonomy' from others and "be true to one's own internal structure of preferences, rights, convictions, and goals"(Markus and Kitayama 1994). On the other hand, persons with interdependent selfconstrual tend to think and behave in ways that represents their connectedness to others. Therefore, it is assumed that consumers with different self-construal can show different in- tentions for their "willingness for prolonged consumption" of milk when they are exposed to external influencer(i.e. KCA test result). In addition, this study has chosen indecisiveness as another consumer characteristic factor which can influence on the decision outcome of "willingness for prolonged consumption." Indecisiveness has been known to be associated with process characteristics of decision making such as decision latency, required amount of information, and reluctant to decide(Germeijs and De Boeck 2002). Indecisiveness causes decision making problems associated with the content of decisions(Buhr and Dugas 2002). For example, indecisive persons are expected to be reluctant to make decisions that will have far reaching consequences. Hence, they are likely to choose conservatively, due to an inherent fear of, or responsibility for change. By this view, indecisiveness fosters cautiousness, resulting in "better safe than sorry" kind of decision making style. Therefore, it is also assumed that consumers with different degree of indecisiveness can show different intentions for their "willingness for prolonged consumption" of milk when they are exposed to external influencer (i.e. KCA test result) due to their innate nature of reluctance to change(Rassin 2004). In sum, this study represents unique work to explicitly investigate different degree of consumers' perceived risk, self-construal, and indecisiveness on their influence on willingness for prolonged consumption on milk as it ages beyond fresh- 
ness labeling when the external influence of safety cue provided by KCA test result.

\subsection{Perceived Risk and Consumers' Intention on Prolonged Consumption}

Introduced by Bauer(1960), the concept of perceived risk is defined as the unexpected and uncertain consequences associated with a product or service that is likely to be unpleasant. Perceived risk is an important construct in social sciences with rich and varied history of research (Campbell and Goodstein 2001). Perceived risk has become one of the central concepts in the marketing literature because it helps to explain the consumer's intention to purchase (Mitchell and Greatorex 1993: Mitchell 1999). It is shown that consumers perception of risk is central to their evaluation and purchasing behaviors(Dowling and Staelin 1994). Perceived risk has two components: uncertainty (the likelihood of unfavorable outcomes) and consequences (a loss)(Bauer 1960). Although Bauer's initial work(1960) reviewed perceived risk as two-dimensional construct, more recent works views it as a multidimensional construct including financial, performance, physical, psychological, and social risks(Havlena and DeSarbo 1990: Jacoby and Kaplan 1972: Murray and Schlacter 1990). Several other potential sources of perceived risk include time risk(Roselius 1971), source credibility risk(McCorkle 1990) and privacy risk(Elliot 1995). A review of these stud- ies reveals that the perceived risk appears to be extremely context-dependent, in which the importance of each dimension may vary across different product categories and situations consumers face. For example, in computer purchase, the performance and financial risks can be high while remaining risks may be low. Bobbit and Dabholker(2001) proposed that some types of risk, such as financial, psychological, and performance risks are more applicable to shopping on the Internet than other traditional shopping methods. In terms of financial risk, consumers may fear that the company that they have knowledge of only through the Internet may have a change to misuse consumers' credit cards. The psychological risk may concern about issue such as personal information spill on the Internet. The performance risk may involve quality of the product which already purchased may not meet the expectation of consumer.

Overall, perceived risk is viewed as subjective expectation of loss(Mitchell and Greatorex 1993: Peter and Ryan 1976). A semantic approach indicates the social risk is defined as the potential loss of esteem, respect and or friendship offered to the consumer by other people(Murray and Schlacter 1990). Time risk is the potential loss of time and effort associated with the activity(Roselius 1971). Source credibility risk reflects concern over credibility on target activity such as source or identity of the product fails to that of consumer's expectation(McCorkle 1990). Psychological risk is the 
potential loss of self-image or self-concept by the result of activity such as poor product choice can harm one's ego(Jacoby and Kaplan 1972: Murray and Schlacter 1990: Roselius 1971). Financial risk is the potential loss of money associated with activity such as the product is not worthy of price being paid(Dunn et al. 1986). Physical risk concerns consumer's safety in using the product(Jacoby and Kaplan 1972). Performance risk relates to potential loss due to functional failure of the item such as product not meeting standards of quality(Dunn et al. 1986: Roselius 1971). Given the nature of the current research, it is expected that source credibility, and physical risks dominate the other risks(i.e. social, psychological, time, and financial). In this study, the source credibility risk comes from the trustworthiness on the food management during the production and distribution processes before they come into consumers' hands. The physical risk involves adverse health effects when "milk gone-bad" is consumed which had passed its freshness labeling.

Prior studies have shown that when risk increases, so do consumers' desire for information before they make decision(Blackwell et al. 2001: Dowling and Staelin 1994: Greenleaf and Lehmann 1995). In an attempt to reduce risk, consumers search for more information before they make decisions on activity such as product purchase. In current research, there are two pieces of information available on consumers: freshness labeling (sell by date), and information provided from $\mathrm{KCA}$ on additional dates to 'safely intake foods' which can be reflected to sell by date, as "best before date." The information on freshness labeling will act as forming of the risk on consumers, because when stamped date is reached, it will function as a "deadline" which will bring about threats caused by consuming the unsafe food hereafter. On the other hand, the information on food test results provided by KCA will bring sense of relief on pressured consumers by food labeling already reached its stamped date. The more risk being conceived, the more impactful the KCA recommendation on person's cognition due to it's the only available source of information consumers need at the time, not to mention trustworthy. Thus, positively conforming behavior toward what KCA suggests(i.e. prolonged consumption of milk beyond its sell by date is not risky) can likely to occur. On this base, we propose following hypothesis:

H1: Compared to a group with moderatechange of intention on prolonged consumption of milk when it reached its stamped date after KCA information is provided, the wide-change group is highly likely to be served by source credibility risk and physical risk.

\subsection{Self-Construal and Consumers' Intention on Prolonged Consumption}

The concept of self is central to an individual's 
perceptions, evaluations, and behaviors(Markus and Kitayama 1994: Triandis 1989). Cultural psychologists have identified a basic dimension which differentiates how individuals think about themselves in the social world such as friendly relationships, contexts for behavior, and memberships(Markus and Kitayama 1994: Shweder and Bourne 1984: Triandis 1989). The focus is on what people believe about the relationship between the self and others, especially the degree to which they see themselves as separate from others or connected with others(Markus and Kitayama 1994). The term "self-construal" is conceptualized as a constellation of thoughts, feelings, and actions concerning the relationship with others, and self as distinct from others (Markus and Kitayama 1994). The underlying principle that shapes independent self-construal is the premise that the individual is essentially separated from others. The primary components of the independent self-construal are unique personal traits, abilities, preferences, interests, goals, and experiences. All these are differentiated from social context, interpersonal relationships, and group memberships. To maintain and enhance this independent view of the self, one must maintain a sense of 'autonomy' from others and "be true to one's own internal structure of preferences, rights, convictions, and goals"(Markus and Kitayama 1994). In contrast, the underlying principle that shapes the interdependent self-construal is the premise that the person is connected to others, so that the self is defined, at least in part, by important roles, group memberships, or relationships. For individuals with interdependent self-construal, representations of important relationships and roles share the self-space with abstract traits, abilities, and preferences. To maintain and enhance interdependence view of the self, individuals tend to think and behave in ways that emphasize their connectedness to others and that strengthen existing relationship(Markus and Kitayama 1994).

The differences in self-construals can raise issues regarding self-related processes. In reaction to incoming information, for those with an independent view of self, this process is rooted to one's self-defining attributes. For those with an interdependent view of self, the process is rooted to in relation with another person. As a result, individuals with an interdependent selfconstrual may attend more closely to information related to others than will individuals with an independent self-construal. In terms of "affect regulation" which involves seeking positive states and avoiding negative ones, positive states are those that enhance or promote individual's view of self , and negative ones are those that challenge this view. For individuals with independent view of self, this involves seeking information that confirms or enhances one's internal private attributes, thereby prefer to verify and express internal attributes and stay autonomous. In contrast, individuals with interdependent view of self would seek information that promotes 
other's goals to adjust, maintain harmony with social context(Markus and Kitayama 1994). Markus and Wurf(1987) suggested motivational processes may also vary individuals with different self-construals. For individuals with an independent view of self are motivated to those stimuli or actions that allow expression of one's important self-defining, and inner attributes, while persons with an interdependent view of self are motivated to stimuli that enhance or foster their relatedness or connection to others (Blaine and Crocker 1993: Harter 1993: Tesser 1986). Therefore, persons with an interdependent view of self may be more likely to self-disclosure on intimate topics or to consider implications of their decisions, compared to those with an independent view of self.

Following Greenwald and Pratkanis(1984), Triandis(1989) conceptualized each person's self as having three aspects: private self, public self, and collective self. The private self is being defined as cognitions that involve traits or behaviors on person implies independent tendencies while collective and public aspects represent interdependent tendencies. In making the decision, persons with private self will find cognitions about individual rights, the value of autonomy, and personal preferences on situations. It was also suggested that if independent self dominates other's advice, even someone very close to self, such as family members or close friends, probably will not have an influence. One could develop both selves: independent and interdependent. In such as case, one would experience a great deal of intrapersonal conflict. The outcome of such conflict may depend on variety of factors other than self-concept(Triandis 1989). According to the idea, it is assumed that information provided from KCA on additional dates to 'safely intake foods' may not have an impact on consumers who have well-developed private self. This means when independent self dominates, consumers will likely to stick to his or her original decision than what recommends from KCA. Therefore, test results provided by KCA will have little or no effect on the change of initial decision made on consumers who have dominant independent view of self. For consumers with interdependent view of self, depending on how well this side of self-concept has been developed, both moderate and wide changes of intention on prolonged consumption can take place, but between the two, it's hard to draw the line. Therefore, we propose following hypothesis:

H2: Compared to a group with moderatechange of intention on prolonged consumption of milk when it reached its stamped date after KCA information is provided, the group with no-change of intention is highly likely to be served by independent self-construal, while the group with wide-change of intention is highly likely to be served by interdependent selfconstrual. 


\subsection{Indecisiveness and Consumers' Intention on Prolonged Consumption}

Indecisiveness has been argued to be associated with process characteristics of decision making such as decision latency, required amount of information, and reluctant to decide(Germeijs and De Boeck 2002). Indecisiveness prevents individuals from organizing their environment and their own thoughts in a quick and consistent manner. It means individuals with an indecisive tendency tend to seek too many ways in which "over-categorizing" or "overstructuring" can occur that will slow down or even cause inability to act appropriately(Tallis 1997). Also indecisiveness causes decision making problems because indecisive individuals require more information before they come to a conclusion. Another consequence of indecisiveness may be that once a decision is made, the individual start to doubt whether the decision already made was the best possible one, thereby whole decsion process begins again. In addition, it seems that indecisive individuals tend to avoid decision making process due to their innate nature of reluctance to do so(Rassin 2004). The decision making problems associated with indecisiveness may also affect content of decisions(Buhr and Dugas 2002). For example, indecisive individuals can be expected to be reluctant to make decisions that will have far reaching consequences. Hence, they are likely to choose conservatively, due to an inherent fear of, or responsibility for change. In addition, indecisive individuals tend to interpret ambiguous situations in a "worst case scenario" fashion. (Buhr and Dugas 2002). By this view, indecisiveness fosters cautiousness, resulting in "better safe than sorry" kind of decision making style. Such a cautious decision making style has already been found to be related to intolerance of uncertainty. Intolerance of uncertainty is akin to indecisiveness and refers to a perceived unacceptability of a possible negative event, however small the probability of its occurrence(Buhr and Dugas 2002). Intolerance of uncertainty is also found to be associated with excessive worrying.

Indecisiveness, compared to decisiveness, report lower levels of self-esteem, competitiveness, and confidence at making decisions (Beswick et al. 1988: Effert and Ferrari 1989). Indecisiveness also are more easily distracted, more likely to incite anger in others and experience interpersonal difficulties, thereby rejecting of good spirited others(Harriott and Ferrari 1996). Therefore, indecision is more than just not making timely decision. Through indecisiveness, individuals may avoid anticipated negative consequences from the process of outcome of a decision. Frost and Shows(1993) found that indecisiveness compared to decisiveness had longer latencies on an experimental decision-making task, when the task was against one's preconception and perceived as unpleasant. Harriott and Ferrari(1996) found that indecisiveness searched for less information compared to decisiveness. When the 
number of alternatives and dimensions increased, the amount of potential information to be searched by indecisive individuals was held constant. However, the amount of cognitive effort to perform the task was increased. Therefore it could be hypothesized that high cognitive effort would cause individuals with indecisiveness to limit the depth of information search. It was also found that under conditions of important cognitive load and self-awareness, individuals with indecisiveness would search for less information. In current study, we assume that when indecisive consumers are confronted with situation to make decisions, and the situation is against or somewhat different from what was anticipated in prior, the consumers will experience feelings of not knowing how to make decisions, and uncertain about the process. This will lead to delay in making decisions at proper time period or even avoid making a decision. If consumers are adhering to "better safe than sorry" kind of decision making mechanism, they will perhaps try to avoid possible negative health outcomes such as stomach problems by consuming what was conceived as the "wrong" product. Thus, information provided by KCA on additional dates to "safely consume perishable foods', will have little effect on their judgment, and indecisive consumers would likely to remain unchanged with their initial judgment on stamped date. Therefore, we propose following hypothesis:

H3: Compared to a group with moderate- change of intention on prolonged consumption of milk when it reached its stamped date after KCA information is provided, the group with no-change of intention is highly likely to be served by indecisiveness.

\subsection{Regulatory Focus and Consumers' Intention on Prolonged Consumption}

Individuals are assumed to be motivated by both positive and negative role models in life. Individuals who have achieved outstanding success in life are widely expected to inspire others to pursue similar excellence: individuals who have experienced misfortune also motivate other people by taking steps necessary to avoid similarly unhappy outcomes. The inspirational impact of positive and negative role model may depend on the goals people are striving to achieve when they encounter situations. Goals can take the form of pursuing desirable or avoiding outcomes(Elliot and Harackiewicz 1996: Higgins 1998). Individuals are likely to be inspired by positive role models, who represent a desired self, when they engage in pursuing success, and by negative role models, when they are intent on avoiding failures. Higgins(1998) suggested that individuals can pursue two different kinds of regulatory goals: promotion and prevention. Promotion goals entail striving to achieve an ideal self, thereby producing sensitivity to the presence or absence of positive outcomes: strategies in achieving promotion goals involve pur- 
suit of gains or successes. In contrast, prevention goals entail striving to avoid misfortunes and disasters, thereby producing sensitivity to the presence or absence of negative outcomes: strategies in achieving prevention goals involve avoidance of losses or failures.

When people are driven by promotion goals, they scrutinize for information that relates on the pursuit of success. They are susceptible to notice and recall information relating to the pursuit of success by others (Higgins and Tykocinski 1992). They are also attuned to emotions relating to the successful or unsuccessful pursuit of positive outcomes such as pleasure and disappointment(Higgins et al, 1997). In addition, they tend to focus on interpersonal strategies designed toward promoting desired outcomes (Higgins et al. 1994). They also tend to show high motivation and persistence on tasks that are framed for promotion (Shah et al. 1998). Therefore people in this state of mind will likely be susceptible to positive role models to pursue positive outcomes. In contrast, when people are driven by prevention goals, they focus on information relevant to the avoidance of failure. They are likely to sensitive in noticing and recalling information relating to the avoidance of failure by others (Higgins and Tykocinski 1992). They are also attuned to emotions relating to the successful or unsuccessful avoidance of negative such as anxiety(Higgins et al. 1997). In addition, they tend to focus on interpersonal strategies aimed toward preventing negative outcomes (Higgins et al. 1994). They also tend to show high motivation and persistence on tasks that are framed for prevention (Shah et al. 1998). Therefore people in this state of mind will likely be susceptible to negative role models to avoid negative outcomes.

Regulatory focus theory proposes that promotion focus and prevention focus differ in their strategic inclinations for achieving desired end states(Higgins et al. 1997). Because a promotion focus involves a sensitivity to positive outcomes, individuals with a chronic or situationinduced promotion focus are inclined to utilize active or leading strategic means(e.g., pursue all means of advancement) to attain their goals. For instance, a promotion-focused student who intends to pursue high exam scores as an accomplishment may approach this desired endstate by studying extra material or organizing a study group with fellow classmates. Conversely, because a prevention focus involves a sensitivity to negative outcomes, individuals with a prevention focus tend to use passive or preventive strategic means(e.g., carefully avoid any mistakes) in order to attain their goals (Yoo et al. 2011). For example, a prevention-focused student pursue high exam scores as an a responsibility might avoid mismatches to this desired end-state by ensuring that he or she knows the required material and avoids any distractions prior to the exam.

The logic of regulatory focus applies to the situations involving choice between stability 
and change are described in the literature on task substitution and on endowment(Kahneman et al. 1990, 1991: Knetsch 1989; Thaler 1980). In both the task substitution and the endowment literatures, when opportunity for change was presented, people did not need to change due to the dissatisfaction with the original alternative. In this type of situation, the new action or object creates choice situation, while the old one remains constant, which functions as the fixed or given condition. As a result of focus on the new alternative, the likely representation of the choice situation is "to take or not to take the new alternative." For this type of representation, an active or risky approach would mean more openness to change, whereas an avoidance or conservative strategy would mean less openness to change. Suppose the old alternative was satisfactory, or the original course of action was not failing, and there was nothing wrong with the object one originally possessed, then the original alternative is considered as relatively safe a choice. It follows that individuals in a prevention focus, because of their concern with safety and security, should favor safe and stability in this situation. Individuals in a promotion focus, however, should be open to changing a satisfactory original alternative for a new alternative in the pursuit of advancement and gain. Therefore, whenever the original alternative is satisfactory, and the new alternative has a potential to offer advancement, individuals in a promotion focus are likely to be more open to change compared to individuals in a prevention focus (Kahneman et al. 1990, 1991: Knetsch 1989: Thaler 1980). In current study, we assume that consumers in promotion focus, will conceive of a new alternative(i.e. recommendation of extra days to safely consume perishable foods from the KCA test result) as new opportunity or chance to view freshness labeling that may be different from their original view point, a last day to consume foods. Thus, even if the idea of regarding freshness labeling as "deadline" was satisfactory, and their action of trashing perfectly safe to intake foods was not "failing" course of action, they may likely switch to a new alternative because they are more open to change, due to the nature of their pursuit of strategic means(i.e. all means of advancement) to attain their goals. On the contrary, consumers in prevention focus, will conceive of a new alternative as uncertain and worrisome, because they are primarily concerned with safety and security, thereby likely to adhere to their original alternative(i.e. initial decision before extra days for safe consumption of perishable foods were recommended by KCA). This is because they are relatively less open to change, due to the nature of their pursuit of strategic means(i.e. carefully avoid any mistakes) to attain their goals. This as a base, we would like to investigate how the regulatory focus, either promotion and prevention, whether chronic or situation-induced 'goal-achieving' state of mind 
a person intends to pursue, influence in the causal relationships between different motives or inclinations as discussed above(i.e. perceived risk, self-construal, and indecisiveness) on different types of consumers intention on prolonged consumption of perishable food product(i.e. milk) which approached its stamped date, is another query we have on our current research. Therefore, we propose following hypotheses:

H4: Compared to a group with moderatechange of intention on prolonged consumption of milk when it reached its stamped date after $K C A$ information is provided, the group with wide-change of intention is highly likely to be served by the moderating effect of positive role models (promotion focus) in the relationship between risk perception and different intentions on consumers' prolonged consumption, while the group with no-change of intention is highly likely to be served by negative role models(prevention focus) in the same causal relationship.

H5: Compared to a group with moderatechange of intention on prolonged consumption of milk when it reached its stamped date after KCA information is, the group with widechange of intention is highly likely to be served by the moderating effect of positive role models in the relationship between self-construal and different intentions on consumers' prolonged consumption, while the group with no-change of intention is highly likely to be served by negative role models in the same causal relationship..

H6: Compared to a group with moderatechange of intention on prolonged consumption of milk when it reached its stamped date after $K C A$ information is provided, the group with wide-change of intention is highly likely to be served by the moderating effect of positive role models in the relationship between indecisiveness and different intentions on consumers prolonged consumption, while the group with no-change of intention is highly likely to be served by negative role models in the same causal relationship

\section{Methodology}

\subsection{Instrument Development}

For all measures of study variables: perceived risk, self-construal, indecisiveness, and regulatory focus, we conducted focus group interview to give retouch on validated measures provided by previous literatures(i.e. Stone and Grønhaug(1993) and McCorkle(1990) for risk perception measures, Singelis(1994) for selfconstrual, Germeijs and De Boeck(2002) for indecisiveness, and Lockwood et al.(2002) for regulatory focus). Two rounds of focus group 
$\langle$ Figure 1〉 Conceptual Model

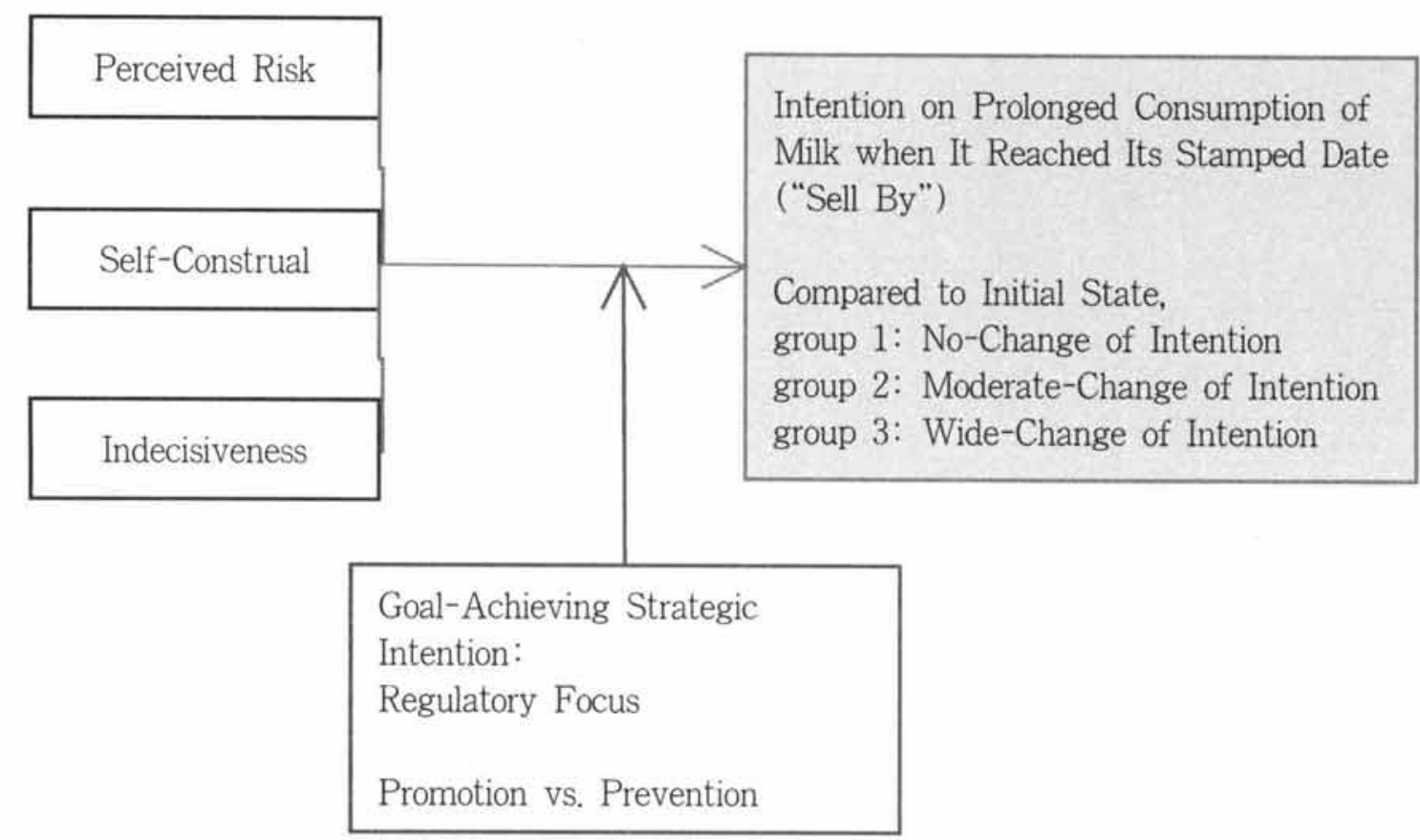

interview sessions were conducted: first on five participants composed of all college students in their 20s in proportion of three males and two females. All of them have no side effects from milk consumption. All of them, at least more than once, have been standing at the crossroads whether to throw away at once, or keep it for little while when the milk reached its date of freshness labeling. All of them, at least more than once, have prior experiences of trashing milk when it did not turn sour, only reached its stamped date. We questioned them what makes them to throw them away. Basically, our study participants were concerned two types of risks: process involved prior to the product reached consumers, and possible adverse health outcomes that may be caused due to consuming milk which has passed its sell-by date. In the second round of focus group interview, three (3) marketing $\mathrm{PhD}$ students are involved to make comparison between the raw data we collected from first round of focus group interviews and different dimensions of risk perception suggested in previous researches(Elliot 1995: Havlena and DeSarbo 1990: Jacoby and Kaplan 1972: McCorkle 1990: Murray and Schlacter 1990: Roselius 1971: Stone and Grønhaug 1993). We primarily focused on measures developed by Stone and Grønhaug(1993) and McCorkle (1990). Finally, it was found that there are two dimensions of risk involved in current study: source credibility risk and physical risk. The source credibility risk relates to consumers' doubt and suspicion on whether the products (i.e. milks) have properly been treated and managed throughout their entire life-cycle starting 
from production process, going on to the distribution system, and finally to consumer's hands, especially in terms of the right temperature. As was found from the KCA report, "keeping them in the right temperature $\left(0 \sim 5^{\circ} \mathrm{C}\right)$ " is the most important factor to have perishable foods in fresh condition longer. It was also reported that if milk is kept at the temperature of equal or above $25^{\circ} \mathrm{C}$, it will soon turn sour far before its stamped date comes. What study participants most concerned was the poor treatment of product in the distribution process rather than production process. Often, they witness a scene where milk and milk products are left unattended outside of the store fridge waiting to be stacked. For small private stores these products are even left alone on the street for a while, no one knows for how long, alighted from the delivery truck, before they make entrance into the store. Feelings of worries formed by these life events on our study participants have been classified into "source credibility risk." Total of four(4) items of source credibility risk are developed, reviewed and finalized: doubts if delivery truck maintains proper temperature, doubts if the store fridge maintains proper temperature, doubts whether products are properly and safely managed by the store personnel, and doubts of quality assurance on unknown brands. The last item concerns with trustworthiness on the quality of products produced by nonfamiliar or new to the marketplace brand, in which they have not gained consumer trust yet. Study participants also worried about adverse health outcomes in case of consuming milk which passed its freshness labeling, which we classified these items into "physical risk." Total of five(5) items of physical risk are developed: risk of being food poisoned, worsen other illnesses or symptoms if body already suffers, possible influence on the long term adverse health effects, simple stomachache or nausea, and degradation of smell and taste due to a lack of freshness or ongoing light spoilage

For measures of self-construal, we used measures of Singelis(1994), in which he developed 24-item self-contrual scale measuring two dimensions of self-image: interdependent and independent. The items developed in the study from samples of undergraduate students in university of Hawaii, were organized from the related previous measures(Hui 1988: Triandis et al. 1986: Triandis et al. 1990. Yamaguchi et al. 1992) first, before finalized into 12-items of independent and 12-items of dependent measures. Since it is argued that both images of self can and do coexist in individuals, and coexistence of two self-construals is not problematic(Cross and Markus 1991), both measures were put to use in our study. From the 12-items of independent self-construal measures, we put to use eight(8)-items and slightly modified them to have better fit for the study purpose: (1) I'd rather say "No" directly rather than having a risk of being misunderstood, (2) having lively self-imagination is very important, (3) being 
singled out for praise or rewards is not a problem, (4) I am the same person regardless of place and situation, (5) being able to take care of myself-care is a primary concern, (6) I behave the same way no matter who I'm with, (7) I prefer to be direct and forthright when dealing with people, and lastly, (8) my personal identity being independent of others is very important. From the 12-items of interdependence self-construal measures, we put to use eight (8)-items and slightly modified them to have better fit for the study purpose: (1) I respect for authority figures when I interact with people, (2) I maintain harmony within the group, (3) my happiness is dependent on other's happiness, (4) I respect modest people, (5) relationship with others is more important than the self-accomplishments, (6) respect on the decisions made by my group, (7) I feel responsibility when my siblings fail, and lastly, (8) I avoid argument with my group even if personally I don't agree with the group decision.

For measure of indecisiveness, we used dimensions suggested by Germeijs and De Boeck (2002), in which they organized existing scales of general indecisiveness from previous literatures(Chartrand et al. 1990: Cooper et al. 1984: Frost and Shows 1993: Jones 1989). The following descriptors for difficulties in making decisions in general are suggested: (1) making decision takes a longtime, (2) finding it difficult to make a decision, (3) not knowing how to make a decision, (4) feelings of uncertainty during the decision making process, (5) delaying a decision, (6) avoiding a decision, (7) leaving a decision to someone else, (8) instability of a decision, (9) worrying about a decision which is already made, (10) regretting a decision that is made, (11) reverse decisions already made. Based on above characteristics concerning indecisiveness suggested, we developed 11-item measures of indecisiveness at the second round of focus group interview. Each item was formulated as a statement for which the subjects have to indicate the extent of agreement on a 7-point Likert scale going from strongly disagree(1) to strongly agree(7).

For measures of regulatory focus, we used measures provided by Lockwood et al.(2002) Since promotion-focused individuals favor a strategy of pursuing desirable outcomes and inspired by positive role models, while preventionfocused individuals favor a strategy of avoiding undesirable outcomes, and motivated by negative role models, the measures in both dimensions are identical for content-wise, except the "goalachieving" strategic intentions are contrary to each other: one is positively oriented while the other is negatively oriented. For example, "I often think about the person I would ideally like to be in the future" in promotion-focused questionnaire is reflected as "I often think about a person I'm afraid I might become in the future" in prevention-focused one. In an effort to distinguish our sample population into individuals with more promotion-focused orientation, and 
with more prevention-focused nature, the current study developed 7-point semantic differential scales. In semantic differential scale, we constructed each end point, 1 and 7 contain bipolar labels that describe semantic meanings of promotion-focus and prevention-focus. Total of 9-items of regulatory focus measures are developed in the form the following descriptors being used in scale point 1 and 7 respectively: (1) In general, I am focused on achieving positive outcomes in my life-In general, I am focused on preventing negative events in my life, (2) I frequently imagine how I will achieve my hopes and aspirations-I am anxious that I will fall short of my responsibilities and obligations, (3) I often think about the person I would ideally like to be in the future-I often think about the person I am afraid I might become in the future, (4) I often think about how I will achieve academic success-I often worry that I will fail to accomplish my academic goals, (5) I often imagine myself experiencing good things that I hope will happen to me-I often imagine myself experiencing bad things that I fear might happen to me, (6) I typically focus on the success I hope to achieve in the future-I frequently think about how I can prevent failures in my life, (7) I am more oriented toward achieving success than preventing failure-I am more oriented toward preventing losses than I am toward achieving gains, (8) My major goal in school right now is to achieve my academic ambitions-My major goal in school right now is to avoid becoming an academic failure, (9) I see myself as someone who is primarily striving to reach my "ideal self", to fulfill my hopes, wishes, and aspirations-I see myself as someone who is primarily striving to become the self I "ought" to be, to fulfill my duties, responsibilities, and obligations.

\subsection{Sample and Date Collection}

The data were collected through off-line survey, primarily on college students. The sample population constitutes ages between 20 s to 30 s who had prior experiences of at least more than once, trashing milk when it did not turn sour, only reached its stamped date, who also have been standing at the crossroads whether to throw away at once, or keep it for little while when milk has reached its date of freshness labeling. Total of 292 questionnaires were distributed and 276 valid ones are obtained. The demographic characteristic on sample population showed following compositions: males $153(55.4 \%)$, females $123(44.6 \%)$, married 267 $(96.7 \%)$, single $9(3.3 \%)$, ages between $20-24$ is $192(69.6 \%)$, between $25-29$ is $72(26.1 \%)$, and 30 and over is $12(4.3 \%)$. In terms of education, high school graduates are $3(1.1 \%)$, some college is $222(80.4 \%)$, college graduate is $27(9.8 \%)$. some graduate school is $15(5.4 \%)$, and graduate school degree is $9(3.3 \%)$. For occupations, students are $234(84.8 \%)$, office management workers are $18(6.5 \%)$, professionals are $15(5.4 \%)$, 
technical posts are $3(1.1 \%)$, and others are $6(2.2 \%)$. Our study participants were presented with two different sized milks: $200 \mathrm{ml}$ smaller size and $1,000 \mathrm{ml}$ larger size, and were asked on their intention for prolonged consumption after it has reached its date of freshness labeling at two time periods: pre-KCA result being shown(i.e. before) and post-KCA result being shown(i.e. after). For "before" measures, on small sized milk $(200 \mathrm{ml})$, the average intention on prolonged consumption, was about two(2) more days, while on large sized milk $(1,000 \mathrm{ml})$, the average was also two(2) more days. For "after" measures, on small sized milk $(200 \mathrm{ml})$, the average intention on prolonged consumption, was about nine(9) more days, while on large sized milk $(1,000 \mathrm{ml})$, the average was 11 more days. Our study participants were also presented with two different brands of milk asking their intention on prolonged consumption: famous brand, and no name brand. For famous brand, the average intention on prolonged consumption was two(2) (for "after" measure it was ten(10)) more days, while for no name branded milk, the average was one(1) (for "after" measure it was eight(8)) more days. We conducted paired t-test to see if the display of KCA test result on study participants has significantly increased their intention for prolonged consumption of milk compared to the initial, unexposed state(i.e. comparison between "before" and "after" measure). For small sized milk $(200 \mathrm{ml})$, we have t-statistics value of $-10.473(d f=275, p=0.000)$. For large sized milk $(1,000 \mathrm{ml})$, we have t-statistics value of $-10.087(\mathrm{df}=275, \mathrm{p}=0.000)$. For famous branded milk, we have t-statistics value of $-10.543(d f=275, p=0.000)$. And for no name branded milk, we have $t$-statistics value of $-9.763(d f=275, p=0.000)$. Therefore our study participants showed favorable attitude on KCA test result for different sized and branded milks. On questions asking previous experiences on adverse health effect after consuming perishable foods that have passed stamped date, our study participants suffered with such symptoms as nausea, stomachache, diarrhea, heartburn, and food poisoning.

During the two rounds of data collection, study participants are presented with today's date and picture of milk first, and indicated that stamped date(i.e. sell by) on milk is today: today being the dead line. Then, they were asked to write number of days in the blank, provided by the survey sheet regarding their initial intention on prolonged consumption (pre-KCA result being shown) of milk beyond sell by date. On the following page, KCA test results on recommendation for extra days to safely consume perishable foods are shown with pictures and descriptions, along with definitions of sell by date and best before date. Such perishable foods as cake, fresh cream, loaf of bread, frozen dumplings, milk, and cheese are presented with their "best before" dates and along with proper temperatures for storage. On 
the following page, another round of data collection of consumers intention on prolonged consumption of milk beyond sell by date is conducted(post-KCA result being shown). The difference in dates between the initial and post measurements are calculated for each $\mathrm{re}^{-}$ spondent to be able to divide them into different groups of intentions for prolonged consumption. As was suggested previously, a total of three groups made appearances: no-change group(a group with unchanged intention), moderatechange group(a group with moderate change in intention), and wide-change group(a group with wide change in intention). No-change group is the group whose "after" intention has not changed compared "before" one, there by difference in dates is zero. For example, if a respondent claimed that he would like to consume milk for two more days after sell-by date initially, and his second round response on the same question, on exposure to KCA test results was also two more days, this candidate belongs to no-change group. Between the moderate-change group and wide-change group, it was difficult to decide where to draw the line. Since, distribution curve in frequency measure of the study population started to decrease after five(5) days, we decided to set cut off point at five(5) days. Total number of people who belonged in no-change group is 51 , in moderate-change group is 129 , and in wide-change group is 96 . Then we conducted chi-square test to see if such classification is statistically significant. We have chi-square value of $33.326(\mathrm{df}=2, \mathrm{p}=0.000)$ which indicated these three(3) groups showed significantly different intentions on prolonged consumption from one another. Therefore, setting no-change group at zero(0) days, moderate-change group at 1-5 days, and wide-change at 6-55 days is grouping scheme we employed. To ensure the validity of our grouping scheme further, we also conducted chi-square test to see if such scheme is also significant on groups with different classification criteria we impose on our sample population: small sized milk $(200 \mathrm{ml})$, large sized milk $(1,000 \mathrm{ml})$, famous brand, and no name brand. For small sized milk, we have chi-square value of $18.065(\mathrm{df}=2, \mathrm{p}=0.000)$. For large sized milk, we have chi-square value of $31.370(d f=2, p=0.000)$. For famous branded milk, we have chi-square value of $44.087(\mathrm{df}=2$, $\mathrm{p}=0.000$ ). And for no name branded milk, we have chi-square value of $13.565(\mathrm{df}=2, \mathrm{p}=0.001$ ). In all occasions, our grouping scheme is found to be statistically significant.

\section{Analyses and Results}

\subsection{Test for Moderating Effect}

To test for the moderating effect of regulatory focus on groups with different intentions on prolonged consumption, we conducted chisquare test to see if grouping scheme on this 
construct is significant. For measures of regulatory focus, we developed 7-point semantic differential scales to distinguish our sample population between promotion-focused group and prevention-focused group. Those marked their responses near point-1 are having promotion-focused orientation, while those put their responses near point- 7 are having preventionfocused orientation. Participants are categorized into promotion-focused and prevention-focused groups on a median-split procedure, used as cut-off techniques in previous research on regulatory focus(Liberman et al. 1999: Lockwood et al. 2002). The median for regulatory focus on our sample population is 4.8, and there are 27 participants who belong in this category. There are 123 people who belong to promotionfocused group, and 126 people who belong to prevention-focused group. Therefore, total of 249 sample population, exempting 27 people who belong in median group are analyzed for testing of the moderating effect. The cross tabulation showed that there are 24 individuals in nochange group, 69 in moderate-change group, and 30 in wide-change group who showed promotion-focused orientation. On the other hand, there are 21 in no-change group, 45 in moderate-change group, and 60 in wide-change group who showed prevention-focused orientation. We have chi-square value of $15.219(\mathrm{df}=2, \mathrm{p}=0.000$ ) which showed that all three(3) groups with different intentions on prolonged consumption are statistically significant one another when they are divided into promotion-focused and prevention-focused groups. Therefore, significant group difference exists across different goalachieving strategic intentions of people, the positive or negative state of mind.

\subsection{Factor Analysis}

To understand underlying structure of construct, principal component factor analysis with varimax rotation is conducted. To see if preconditions to conduct factor analysis, $\mathrm{KMO}$ and Bartlett's test of sphericity and measures of sampling adequacy are conducted before conducting factor analyses to see if preconditions are met. The priori constraints on the estimation of components were left to open. The rationale for this is to see whether our conceptual domains of risk perception, self-construal, and indecisiveness stand. The criteria for extraction were set at eigen values of 1.0 or higher, and factor loadings for over 0.5 . All items of risk perception, self-construal, and indecisiveness are put together to run analysis. Total of 27 -items resulted with five(5) factor solutions: source credibility risk, physical risk, independent selfconstrual, interdependent self-construal, and indecisiveness. Cronbach's Alpha coefficients were calculated for each factor scale to assess internal consistency which ranged from 0.649 (independent self-construal) to 0.929 (physical risk). All values are well within the range of 0.5(Hair Jr, et al. 2010) or 0.6 (Tabachnick and 
Fidell 1996). A scree plot revealed a flattening of the curve for all factors below the first five. Therefore five-factor solution conservatively appears to be interpretable, accounting for $59.9 \%$ of the total variance.

For risk perception measures, total of nine(9) -items resulted with two factor solutions: source credibility risk(4) and physical risk(5) without any eliminated items. For source credibility risk, the items are: doubts if delivery truck maintains proper temperature, doubts if the store fridge maintains proper temperature, doubts whether products are properly and safely managed by the store personnel, and doubts of quality assurance on unknown brands. For physical risk, the items are: risk of being food poisoned, worsen other illnesses or symptoms if body already suffer, possible influence on the long term adverse health effects, simple stomachache or nausea, and degradation of smell and taste due to a lack of freshness or ongoing light spoilage. Cronbach's Alpha coefficients were calculated for each factor scale to assess internal consistency which ranged from 0.837 (source credibility risk) to 0.929 (physical risk). For self-construal which measures two dimensions of self-image: interdependent and independent, are also subjected for factor analysis with varimax rotation. From the 24 -items of previously validated scales of Singelis(1994). we started off with 16-items of measures: eight (8) independent and eight(8) interdependent self-construal measures, with a touch of slight modifications were undergone to make sure, all items tap the domains of construct. Total of ten(10)-items resulted with two factor solutions: independent self-construal(4), and interdependent self-construal(6). Four items were eliminated from independent self-construal, while only two items were eliminated from the measures of interdependent self-construal. For independent self-construal, the items survived are: I'd rather say "No" directly rather than having a risk of being misunderstood: having lively self-imagination is very important: I am the same person regardless of place and situation; and I behave the same way no matter who I'm with. The items dropped are: being singled out for praise or rewards is not a problem: being able to take care of myself-care is a primary concern: I prefer to be direct and forthright when dealing with people: and my personal identity being independent of others is very important. For interdependent self-construal, the items survived are: I maintain harmony within the group: my happiness is dependent on other's happiness: I respect on modest people: respect on the decisions made by my group: I feel responsibility when my siblings fail; and I avoid argument with my group even if personally I don't agree with the group decision. The items eliminated are: I respect for authority figures when I interact with people, and relationship with others is more important than the self-acomplishments. Cronbach's Alpha coefficients were calculated for each 
$\langle$ Table 1〉 Five Factor Solution with Items Survived

\begin{tabular}{|c|c|c|}
\hline & Items Survived & Items Dropped \\
\hline Source Credibility Risk(4) & $\begin{array}{l}\text { truck temperature, store fridge } \\
\text { temperature, safe management by } \\
\text { store personnel, unreliable brands }\end{array}$ & none \\
\hline Physical Risk(5) & $\begin{array}{l}\text { food poisoning, worsen other illnessed } \\
\text { body suffers, long-term adverse } \\
\text { health effect, simple stomachache or } \\
\text { nausea, degradation of food quality }\end{array}$ & none \\
\hline Independent Self-Construal(4) & $\begin{array}{l}\text { say "no" directly, self-imagination, } \\
\text { same person all the time, consistent } \\
\text { behavior, }\end{array}$ & $\begin{array}{l}\text { singled out is no problem, take care } \\
\text { of self being the most important, be } \\
\text { direct in dealing with other people, } \\
\text { identity being independent of others }\end{array}$ \\
\hline Interdependent Self-Construal(6) & $\begin{array}{l}\text { harmony with other people, other's } \\
\text { happiness is important, respect on } \\
\text { modest people, respect group } \\
\text { decisions, responsible for my siblings' } \\
\text { failure, avoidance of argument, }\end{array}$ & $\begin{array}{l}\text { respectful for authority figure, } \\
\text { relationship is more important than } \\
\text { self accomplishment. }\end{array}$ \\
\hline Indecisiveness (8) & $\begin{array}{l}\text { hard to make decision, hesitate to } \\
\text { make decision, takes long time to } \\
\text { make decision, delay making decision, } \\
\text { avoid making decision, reconsider } \\
\text { decision already made, worry, regret } \\
\text { about decision already made }\end{array}$ & $\begin{array}{l}\text { don't know how to make decision, } \\
\text { uncertain to make decision, leave } \\
\text { decision to someone else }\end{array}$ \\
\hline
\end{tabular}

factor scale to assess internal consistency which ranges from 0.649 (independent self-construal) to 0.709 (interdependent self-construal).

For indecisiveness, we started off with 11items of previously validated scales of Germeijs and De Boeck(2002), total of eight(8)-items resulted with three items were eliminated. The items survived are: it's hard for me to come to a decision: I hesitate much when I have to make a decision: It takes a long time before making a decision; I delay making decisions: I try to avoid making a decision: I often reconsider my decision: after making a decision, I worry about it much: and after I have decided something, I often think that I made a wrong decision. The items eliminated are: I don't know how to make decision: while making a decision I feel uncertain: and I tend to leave decisions to someone else. Cronbach's Alpha coefficient was calculated to assess internal consistency which was 0.877 on all eight-items survived.

All measures above were conducted with confirmatory factor analyses in an effort to ensure validation of scales for the developed measures. Since some of the measurement items are 
〈Table 2〉 Result of Factor Analysis

\begin{tabular}{|c|c|c|c|c|c|}
\hline Items & Factor1 & Facor2 & Factor3 & Factor4 & Factor5 \\
\hline Hard to make & .878 & .063 & .011 & -.081 & .080 \\
\hline Hesitate to make & .841 & .110 & .109 & -.042 & -.091 \\
\hline Takes long time & .831 & .144 & -.077 & .013 & .020 \\
\hline Delay to make & .738 & -.189 & .015 & .014 & -.238 \\
\hline Avoid to make & .612 & -.079 & .114 & -.107 & -.354 \\
\hline Reconsideration & .594 & -.235 & .204 & -.115 & -.165 \\
\hline Worry about & .569 & -.178 & .185 & -.064 & -.252 \\
\hline Regret after & .522 & -.054 & .048 & -.302 & -.160 \\
\hline Food poisoning & -.050 & .895 & .067 & -.008 & .053 \\
\hline Worsen other illnesses & -.087 & .889 & .223 & .072 & -.008 \\
\hline Adverse health effect & -.005 & .859 & .086 & .018 & .004 \\
\hline Stomachache or nausea & .011 & .859 & .159 & .017 & -.036 \\
\hline Degradation of food quality & -.083 & .794 & .299 & -.058 & .087 \\
\hline Truck temperature & .104 & .104 & .864 & .000 & -.080 \\
\hline Store fridge temperature & .173 & .183 & .783 & .088 & -.069 \\
\hline Safe management by store personnel & .010 & .237 & .758 & -.104 & .090 \\
\hline Unreliable brands & .078 & .184 & .742 & -.111 & -.045 \\
\hline Harmony & -.191 & .125 & .055 & .750 & -.162 \\
\hline Other's happiness & -.212 & -.019 & -.038 & .644 & .297 \\
\hline Respect modest people & .102 & .070 & -.026 & .620 & .366 \\
\hline Group decision & .045 & -.114 & -.010 & .597 & -.002 \\
\hline Responsible for sibling & -.030 & -.073 & -.112 & .587 & -.008 \\
\hline Avoid argument & -.169 & .130 & .013 & .568 & -.115 \\
\hline Direct "No" & -.215 & -.069 & .051 & -.146 & .663 \\
\hline Self-imagination & -.280 & .025 & -.018 & -.005 & .647 \\
\hline Same person anytime & -.333 & -.013 & -.119 & .021 & .646 \\
\hline Consistent behaviors & .068 & .087 & -.013 & .163 & .601 \\
\hline Factor Name & Indecisiveness & $\begin{array}{c}\text { Physical } \\
\text { Risk }\end{array}$ & $\begin{array}{c}\text { Source } \\
\text { Credibility }\end{array}$ & $\begin{array}{l}\text { Interdependent } \\
\text { Self-Construal }\end{array}$ & $\begin{array}{l}\text { Independent } \\
\text { Self-Construal }\end{array}$ \\
\hline Eigen Value & 4.465 & 4.070 & 2.805 & 2.603 & 2.245 \\
\hline Variance Explained (\%) & 16.538 & 15.075 & 10.388 & 9.642 & 8.314 \\
\hline
\end{tabular}

modified and even newly developed(risk perception measures) to fit for the practical purpose of the study, the exploratory technique we conducted in prior may have limited control over finalizing items to variables. Therefore, in prior to finalizing items by only allowing the statistical method to determine the number of factors and loading as in exploratory factor analysis, we wanted to make sure how well our theoretical specification of factors matches 
〈Table 3〉 CFA on Theories of Attitude

\begin{tabular}{|c|c|c|c|}
\hline Items & $\begin{array}{l}\text { Standardized } \\
\text { loading }\end{array}$ & Composite reliability & AVE \\
\hline Hard to make & 0.863 & \multirow{8}{*}{0.888} & \multirow{8}{*}{0.506} \\
\hline Hesitate to make & 0.903 & & \\
\hline Takes long time & 0.727 & & \\
\hline Delay to make & 0.598 & & \\
\hline Avoid to make & 0.567 & & \\
\hline Reconsideration & 0.599 & & \\
\hline Worry about & 0.775 & & \\
\hline Regret after & 0.566 & & \\
\hline Food poisoning & 0.773 & \multirow{5}{*}{0.920} & \multirow{5}{*}{0.699} \\
\hline Worsen other illnesses & 0.965 & & \\
\hline Adverse health effect & 0.733 & & \\
\hline Stomachache or nausea & 0.872 & & \\
\hline Degradation of food quality & 0.817 & & \\
\hline Truck temperature & 0.873 & \multirow{4}{*}{0.841} & \multirow{4}{*}{0.576} \\
\hline Store fridge temperature & 0.870 & & \\
\hline Safe management by store personnel & 0.629 & & \\
\hline Unreliable brands & 0.624 & & \\
\hline Harmony & 0.617 & \multirow{6}{*}{0.865} & \multirow{6}{*}{0.520} \\
\hline Other's happiness & 0.794 & & \\
\hline Respect modest people & 0.609 & & \\
\hline Group decision & 0.790 & & \\
\hline Responsible for sibling & 0.773 & & \\
\hline Avoid argument & 0.718 & & \\
\hline Direct "No" & 0.845 & \multirow{4}{*}{0.823} & \multirow{4}{*}{0.541} \\
\hline Self-imagination & 0.606 & & \\
\hline Same person anytime & 0.754 & & \\
\hline Consistent behaviors & 0.716 & & \\
\hline
\end{tabular}

the actual date we collected. Therefore, instead of statistical technique assigns variables to factors, we make this assignment based on our logic being tested before results can be obtained in CFA. The results are described in following table.

The results indicated that all standardized loadings are above 0.5 , average variance extracted and composite reliabilities are greater than 0.5 and 0.7 respectively, which are well within the ranges of guidelines offered by (Hair Jr. et al. 2010). The model fit was good, all within the recommended criteria(Hair Jr. et al. 2010). We can safely ensure validation of scales 
for the developed measures.

\subsection{Hypotheses Testing}

To test hypotheses, we conducted logistic regression analysis. Logistic regression is a form of regression that is formulated to predict and explain a binary (two-group) categorical variable rather than metric dependent measure. Bothe logistic regression and discriminant analysis appropriate techniques when the dependent variables are categorical as in our study. The discriminant analysis is also capable of handling two or more groups of dependent variables, whereas logistic regression analysis is basically limited in its form to two groups. However, logistic regression analysis can handle more than two groups and is capable of combing with other multivariate techniques such as factor analysis and path analysis (Hair Jr. et al. 2010). Moreover, the method can handle categorical independent variables easily, especially in generating dummy variables(regulatory focus measures are dummy coded in our study) whereas in discriminant analysis, dummy variables can often create problems. However the results from both analyses are identical in terms of their interpretation. Therefore, this study prefers logistic regression analysis method due to more widely used these days, and is more powerful alternative tool to discriminant analysis(Hair Jr. et al. 2010).

To assess overall model fit in relationship be- tween perceived risks to groups with different intentions on prolonged consumption, a logistic regression analysis is estimated based on 276 valid observations. The log likelihood value $(-2 L L)$ is 518.114 , with chi-square value of 8.304 $(\mathrm{df}=4, \mathrm{p}=0.031)$ which makes it statistically significant. In estimation of the likelihood of wide-change group is influenced by source credibility risk and physical risk, only source credibility risk $(B=0.180, p=0.024)$ showed significance compared to moderate-change group. Unlike our previous assumption, the physical $\operatorname{risk}(B=0.011, p=0.912)$ is found not to be significantly influencing wide-change group(partly supporting $\mathrm{H1}$ ). To assess overall model fit in relationship between self-construals to groups with different intentions on prolonged consumption, a logistic regression analysis is estimated and log likelihood value(-2LL) is 505.401, with chi-square value of $13.352(\mathrm{df}=4, \mathrm{p}=0.010$ ) which makes it statistically significant. In estimation of the likelihood of no-change group is influenced by independent self-construal, while wide-change group is influenced by interdependent self-construal, only independent self-construal ( $B=0.401, p=0.008)$ showed significance compared to moderate-change group. Unlike our previous assumption, the interdependent selfconstrual $(B=-0.106, p=0.581)$ is found not to be significantly influencing wide-change group (partly supporting H2). To assess overall model fit in relationship between indecisiveness to groups with different intentions on prolonged 
consumption, a logistic regression analysis is estimated and log likelihood value (-2LL) is 287.562, with chi-square value of $6.114(\mathrm{df}=2$, $\mathrm{p}=0.047)$ which makes it statistically significant. In estimation of the likelihood of no-change group is influenced by indecisiveness, significant result is produced in the negative direction $(B=$ $-0.305, p=0.025$ ) (not supporting for $\mathrm{H} 3$ ). This indicates that instead of no-change group, the "wide-change" group is influenced by indecisiveness. The results are indicated in the following table.

We test moderated influence of regulatory focus: promotion-focused versus preventionfocused individuals, on causal relationship between perceived risks to groups with different intentions on prolonged consumption. The 10gistic regression analysis is estimated based on 276 valid observations. The log likelihood value(-2LL) is 456.837 , with chi-square value of 46.453( $\mathrm{df}=8, \mathrm{p}=0.000)$ which makes it statistically significant. The assumption on promotion-focused consumers having wide-change in intention on prolonged consumption for reasons of perceived risks: source credibility $(B=0.029$, $\mathrm{p}=0.850)$ and physical risk reason $(\mathrm{B}=0.019$, $p=0.883$ ), did not hold significance (not supporting for promotion-focus part of H4). The assumption on prevention-focused consumers having no-change in intention on prolonged consumption for reasons of negatively perceived risks: source credibility $\operatorname{risk}(\mathrm{B}=-0.947, \mathrm{p}=$ $0.000)$ and physical risk $(B=-0.535, p=0.002)$ reasons holds significance(supporting for prevention-focus part of $\mathrm{H} 4$ ). The negative sign indicates negatively perceived level of risks in which, both source credibility and physical risks are low or no risks on these dimensions are perceived. The results are indicated in the following table.

The moderated effect of regulatory focus on causal relationship between self-construals: independent and interdependent to groups with different intentions on prolonged consumption is conducted. The logistic regression analysis is estimated. The log likelihood value(-2LL) is 474.270 , with chi-square value of $35.011(\mathrm{df}=8$,

〈Table 4〉 Hypotheses Testing 1 3

\begin{tabular}{c|c|c|c|c|c}
\hline $\begin{array}{c}\text { Types of Intentions for } \\
\text { Prolonged Consumption }\end{array}$ & Independent variable & $\mathrm{B}$ & $\mathrm{SE}$ & $\mathrm{P}$ & Testing Result \\
\hline WIDE-change in Intention & Source Credibility Risk & 0.180 & 0.101 & 0.024 & Partly Supporting H1 \\
\hline NO-change in Intention & Independent Self-Construal & 0.401 & 0.152 & 0.008 & Partly Supporting H2 \\
\hline NO-change in Intention & Indecisiveness & -0.305 & 0.136 & 0.025 & $\begin{array}{c}\text { Not Supporting H3 } \\
\text { (Instead of NO-change } \\
\text { intention, indecisiveness is } \\
\text { supporting for } \\
\text { WIDE-change intention) }\end{array}$ \\
\hline
\end{tabular}


〈Table 5〉 Hypotheses Testing 4

\begin{tabular}{c|c|c|c|c|c}
\hline $\begin{array}{c}\text { Types of Intentions for } \\
\text { Prolonged Consumption }\end{array}$ & Independent variable & $\mathrm{B}$ & $\mathrm{SE}$ & $\mathrm{P}$ & Testing Result \\
\hline NO-change in Intention & $\begin{array}{c}\text { Prevention-focus * } \\
\text { Source Credibility Risk }\end{array}$ & -0.947 & 0.255 & 0.000 & $\begin{array}{c}\text { Prevention-focus part of H4 is } \\
\text { supporting only for reasons of } \\
\text { negative source credibility risk } \\
\text { and physical risk }\end{array}$ \\
\hline NO-change in Intention & $\begin{array}{c}\text { Prevention-focus * } \\
\text { Physical Risk }\end{array}$ & -0.535 & 0.172 & 0.002 & \begin{tabular}{c} 
and phe \\
\hline
\end{tabular}
\end{tabular}

$\mathrm{p}=0.000$ ) which makes it statistically significant. The assumption on promotion-focused consumers having wide-change in intention on prolonged consumption for reasons of self-construals: independent $(B=-0.023, p=0.814)$ and interdependent reason $(B=0.378, p=0.042)$, holds significance only for a reason of interdependent self-construal(partly supporting for promotionfocus part of H5). The assumption on prevention-focused consumers having no-change in intention on prolonged consumption for reasons of self-construals: independent self-con$\operatorname{strual}(B=0.901, p=0.001)$ and interdependent self-construal $(B=-0.562, \quad p=0.030)$ reasons holds significance(supporting for prevention- focus part of H5). Again, the negative sign indicates that prevention-focused individuals having no-change in intention on prolonged consumption for reasons of negatively perceived interdependent self-construal. The results are indicated in the following table.

The moderated effect of regulatory focus on causal relationship between indecisiveness to groups with different intentions on prolonged consumption is conducted. The logistic regression analysis is estimated. The log likelihood val$\mathrm{ue}(-2 \mathrm{LL})$ is 330.608 , with chi-square value of $30.599(\mathrm{df}=4, \mathrm{p}=0.000)$ which makes it statistically significant. The assumption on promotionfocused consumers having wide-change in in-

〈Table 6〉 Hypotheses Testing 5

\begin{tabular}{c|c|c|c|c|c}
\hline $\begin{array}{c}\text { Types of Intentions for } \\
\text { Prolonged Consumption }\end{array}$ & Independent variable & $\mathrm{B}$ & $\mathrm{SE}$ & $\mathrm{P}$ & Testing Result \\
\hline WIDE-change in Intention & $\begin{array}{c}\text { Promotion-focus * } \\
\text { Interdependent } \\
\text { Self-Construal }\end{array}$ & 0.378 & 0.192 & 0.042 & $\begin{array}{c}\text { Promotion-focus part of H5 } \\
\text { is partly supporting for a } \\
\text { reason of interdependent } \\
\text { self-construal }\end{array}$ \\
\hline NO-change in Intention & $\begin{array}{c}\text { Prevention-focus * } \\
\text { Independent Self-Construal }\end{array}$ & 0.901 & 0.266 & 0.001 & \multirow{2}{*}{$\begin{array}{c}\text { Prevention-focus part of } \\
\text { NO-change in in supporting }\end{array}$} \\
\hline
\end{tabular}


〈Table 7〉 Hypotheses Testing 6

\begin{tabular}{|c|c|c|c|c|c|}
\hline $\begin{array}{l}\text { Types of Intentions for } \\
\text { Prolonged Consumption }\end{array}$ & Independent variable & B & SE & $\mathrm{P}$ & Testing Result \\
\hline WIDE-change in Intention & $\begin{array}{l}\text { Promotion-focus * } \\
\text { Indecisiveness }\end{array}$ & -0.371 & 0.143 & 0.048 & \multirow{2}{*}{$\begin{array}{l}\text { H6 is supporting } \\
\text { (no-change in intention is } \\
\text { shifted to wide-change in } \\
\text { intention due to strong } \\
\text { influence of promotion-focus) }\end{array}$} \\
\hline NO-change i & $\begin{array}{l}\text { Prevention-focus * } \\
\text { Indecisiveness }\end{array}$ & -0.526 & 0.165 & 0.001 & \\
\hline
\end{tabular}

tention on prolonged consumption holds significance for a reason of indecisiveness $(B=-0.371$, $\mathrm{p}=0.048$ ) but in negative direction (supporting for promotion-focus part of H6). As was found in hypothesis 3 , indecisiveness influences "widechange" in intention, instead of no-change in intention. Thus, having a negative result indicates that negative-indecisiveness, i.e. "decisiveness" is functioning on the consumers" intention(i.e. no-change in intention). However due to the fact that promotion-focus supports for "widechange" in intention, consumers' no-change in intention now shifts to wide-change in intention. This implies that decisive consumers who originally support for no-change in intention, if they are promotion-oriented they tend to go for the wide-change in intention, instead. This implies the moderating effect of promotion-focus may hold a dominant position over the causal effect of indecisiveness. The assumption on preventionfocused consumers having no-change in intention on prolonged consumption holds significance for a reason of indecisiveness $(B=-0.526$, $p=0.001$ ) (supporting for prevention-focus part of H6). Again, the negative sign indicates that prevention-focused individuals having no-change in intention on prolonged consumption for reasons of negatively perceived indecisiveness(i.e. decisiveness). The results are indicated in the following table.

\section{Conclusions and Suggestions}

In present study, we set out to explore the relationship between consumers' underlying motives and their intention on prolonged consumption of perishable food(i.e. milk) beyond its date of freshness labeling. The freshness labeling on perishable foods influences consumers' evaluation on food quality more than the actual condition of the food. It acts as a point of reference on consumers' judgment of food whether it is fresh or not. For such a reason many safe to intake foods are trashed due to the fact that consumers inwardly admit freshness labeling as the end of its shelf-life. Through two rounds of focus group interview sessions, we found out consumers' food-trashing involves the percep- 
tion of risks: source credibility risk and physical risk. The source credibility risk comes from doubts during the distribution process before the products come into the hands of consumers, while physical risk involves possible adverse health outcomes consuming the 'milk gone-bad.' If the perception of risk arises from the milk about to consume when its stamped date is already due, the KCA recommendation on prolonged consumption can be influential on consumers due to the trustworthiness of the information source. This, in turn, will expect to create positively conforming behavior of consumers toward KCA recommendation. However, the result indicated that only source credibility risk was significantly reacted by the KCA recommendation. Initially, we put more emphasis on the influence of physical risk over source credibility risk because KCA test results contained "physical-side" of safety(i.e. physical risk) rather than "process-side" of safety(i.e. source credibility risk). In addition, it was found that many of our study participants have past experiences of adverse health effects associated with consumption of foods "gone-bad." About $44 \%$ (121) of study participants have past experiences with consuming foods beyond the expiration dates. Such foods as milk, yogurt, bread, cheese, and even dried seaweed rolls (gimbap) are some of the food examples found which accompanied adverse health conditions when foods beyond expiration dates are consumed. Such conditions as nausea, stomachache, diar- rhea, heartburn, and even food poisoning are the symptoms they suffered in the past. On duration of illnesses, from one day to maximum 26 days are reported in suffering with such symptoms. It is believed that perhaps these direct negative personal experiences from consuming of bad foods hold dominant position in our belief system over the indirect yet trustworthy information provided by KCA: learned by actual experiences come before what secondary information recommends you to do. Therefore, contrary to our initial assumption of "physical risk' being impacted by KCA test results, au fond, our participants stick to what they have learned from their past experiences(i.e. adverse health outcomes associated with consuming 'bad-foods') rather than what recommends from the reputable organization. However, this assumption needs to be tested in further research with more sample population.

We have assumed that consumers with independent self-construal will likely to stick to his or her original decision than taking on the recommendation provided by KCA due to the fact that when independent self dominates, other's advice, even someone very close to self, such as family members or close friends, probably will not have an influence. Therefore, test results provided by KCA will have little or no effect on the change of initial decision made on consumers who have dominant independent view of self, holds significant from the result of our statistical analyses. However, the inter- 
dependent self-construal being motivated by KCA recommendation did not make statistical significance on our result. Initially, we have assumed that independent self-construal is oriented to no-change in intention on prolonged consumption while interdependent self-construal is oriented to "some-change" in intention on prolonged consumption. Since this "somechange" can involve both moderate-change in intention and wide-change in intention, depends on how well an individual develops this side of self-concept, he or she may belong to. either moderate-change in intention group or wide-change in intention group. However, as previously stated, drawing a line between who (to do this, each consumer needs to be verified with what level of interdependent self-construal is developed inwardly) belongs to which group(either in moderate-change in intention or wide-change in intention) is extremely difficult to conduct. In addition, our point of reference has set on moderate-change group which makes it even harder to draw the line between the two(i.e. moderate-change vs. wide-change in intentions). If point of reference has set at no-change group instead, perhaps different results may have occurred.

For indecisiveness, we initially assumed that indecisive consumers are likely to adhering to "better safe than sorry" kind of decision making mechanism and thereby avoiding possible negative health outcomes such as stomach problems by consuming what was conceived as the "wrong" product. Which in turn, the information provided by KCA on additional dates to 'safely consume perishable foods', would have had little or no effect on their judgment. Indecisive consumers are likely to remain unchanged and stick to their initial judgment on stamped date. However, these assumptions did not hold. Rather, it was found that decisive consumers go for the wide-change in intention. Ferrari and Dovidio(2000) introduced the concept of procedural tunnel vision fuelled by indecisiveness. One of the significant symptoms showed from such mental state is intra-dimensional search of information. That is to say, these individuals preferably use only one dimension(e.g. peer recommendation) of information, while decisive individuals use both inter and intra-dimensions (e.g. take others' recommendation and at the same time experience it directly) before making decisions. This coincide with the finding of Harriot and Ferrari(1996) in which they have reported indecisive persons search for less information compared to decisiveness in making decisions. As a consequence, indecisive persons tend to ignore other incoming information once they felt satisfied with the initial information they choose to receive, and not interested in another incoming information which is related but not in urgency, hence narrowed decision making strategy can result(Ferrari and Dovidio 2000). Based on the tunnel vision theory, indecisive consumers, although they may have a tendency to have "better safe than sorry" kind 
of mental mechanism, at the same time, they tend to settle for one important information for them to rely on and trust, and their decision making strategy stops there. This implies that indecisive consumers can easily be faltered by the KCA provided information because it is 'the' one important and reliable source of information which in turn, their behavioral change in compliance to KCA recommendation is highly likely to occur.

On looking at the moderating effect of regulatory focus, in all causal relationships, consumers with promotion-focused orientation go for widechange in intention of prolonged consumption while those with prevention-focused orientation go for no-change in intention. Furthermore, the regulatory focus generated even more powerful influences in the main relationship in which, for decisive consumers (who go for no-change in intention), if they are promotion-focused orientation, they tend to go for the wide-change in intention instead. This implies that the regulatory focus holds dominant position over other influencers(i.e. risk perception, self-construals, and indecisiveness) on consumers' prolonged consumption intention, when such conditions are encountered.

According to regulatory focus theory (Higgins 1998: Higgins et al. 1997), a promotion-focus is concerned with approaching matches for the goals of advancement and accomplishment, whereas a prevention-focus is concerned with avoiding mismatches for the goals of safety and security. When the old alternative is satisfactory and an opportunity for change is introduced into the situation, a change has the potential benefit of providing advancement and accomplishment, but it also has the potential cost of introducing unpredictable errors. Conversely, stability or safety has the potential benefit of safety and security, but it also has the potential cost of rejecting a new incoming chance. Thus, consumers in promotion-focus are willing to change if they believe that new alternative is advancement over the original alternative, whereas consumers in prevention-focus feel more obliged to stick with the original alternative as long as it is satisfactory. Now this logic has an important implication on our study. If consumers are reluctant to change from currently satisfied course of action to a new alternative, this situation involves preventionfocused orientation. Therefore, rather than addressing the promotion aspects of situation, focusing on the 'prevention aspects' of situation is recommended. For example, for consumers who are reluctant to consume milk beyond its stamped date, the persuasion should focus on emphasizing the prevention-related(i.e. stability) merits of prolonged consumption(e.g. prolonged consumption is recommended and validated by reputable organization such as KCA (It is important to let people know how reputable organization KCA is), or instruct detailed procedures as to how properly store milk to consume safely beyond its stamped date) and 
or the prevention-related drawbacks(e.g., wasted of natural resources) of trashing the milk in good condition, rather than addressing promotionrelated merits(e.g., more advanced production and logistic systems now makes its freshness even longer than ever before). This is to say. for those promotion-focused consumers (or situations), promotion-related arguments are more effective, while for those prevention-focused consumers(or situations) prevention-related arguments are more effective means of persuasion.

〈Received April 1. 2013〉

〈1st Revised June 14. 2013〉

〈2nd Revised June 25. 2013〉

〈Accepted June 27. 2013〉

\section{References}

Abad, P.L. (2003), "Optimal Pricing and Lotsizing Under Conditions of Perishability, Finite Production, and Partial Backordering and Lost Sale," European Journal of Operations Research, 144 (3), 677-85.

Bauer, Raymond A. (1960), Consumer Behavior as Risk Taking, in Dynamic Marketing for a Changing World, R. S. Hancock, ed. Chicago: American Marketing Association. Beswick, Gery, Esther D. Rothblum, and Leon Mann (1988), "Psychological Antecedents to Student Procrastination," Australian Psychologist, 23 (2), 207-17.
Blackwell, Roger D., Paul W. Miniard, and James F. Engel (2001), Consumer Behavior, 9th ed. Fort Worth, TX: Harcourt. Blaine, B., and J. Crocker (1993), Self-esteem and Self-serving Biases in Reactions to Positive and Negative Events: An Integrative Review, In R. F. Baumeister (Ed.), Self-esteem: The Puzzle of Low Self-regard (pp. 55-85). New York: Plenum Press.

Bobbit, L. Michelle, and Pratibha A. Dabholker (2001), "Integrating Attitudinal Theories to Understand and Predict Use of TechnologyBased Self-Service," International Journal of Service Industry Management, 12 (5). 423-50.

Buhr, K., and M. J. Dugas (2002), "The Intolerance of Uncertainty Scale: Psychometric Properties of the English Version," Behaviour Research and Therapy, 40 (8), 931-45.

Campbell, Margaret C., and Ronald C. Goodstein (2001), "The Moderating Effect of Perceived Risk on Consumers' Evaluations of Product Incongruity: Preference for the Norm," Journal of Consumer Research, 28 (3), 439-49.

Cardello, A. V., and H. G. Schutz (2003), "The Concept of Food Freshness: Uncovering Its Meaning and Importance to Consumers," ACS Symposium Series, 836, 22-41.

C. Snow, and L. Lesher (2000). "Predictors of Food Acceptance, Consumption and Satisfaction 
in Specific Eating Situations," Food Quality and Preference, 11 (3), 201-16.

Chartrand, Judy M., Steven B. Robbins, Weston H. Morrill, and Kathleen Boggs (1990), "Development and Validation of the Career Factors Inventory," Journal of Counseling Psychology, 37 (4), 491-501.

Chun, Young H. (2003), "Optimal Pricing and Ordering Policies for Perishable Commodities," European Journal of Operations Research, 144 (1), 68-82.

Cooper, Stewart E., Dale R. Fuqua, and Bruce W. Hartman (1984), “The Relationship of Trait Indecisiveness to Vocational Uncertainty, Career Indecision, and Interpersonal Characteristics," Journal of College Student Personnel, 25 (4), 353-56.

Cross, S. E., and H. R. Markus (1991), Cultural Adaptation and the Self: Self-construal, Coping, and Stress, Paper presented at the annual meeting of the American Psychological Association, San Francisco.

Dowling, Grahame, and Richard Staelin (1994), "A Model of Perceived Risk and Risk Handling Activities," Journal of Consumer Research, 21 (1), 119-34.

Dunn, Mark G., Patrick E. Murphy, and Gerald U. Skelly (1986), "Research Note: The Influence of Perceived Risk on Brand Preference for Supermarket Products," Journal of Retailing, 62 (2), 204-16

Effert, Barbara R., and Joseph R. Ferrari (1989), "Decisional Procrastination: Examining Per- sonality Correlates," Journal of Social Behavior and Personality, 4 (1), 151-61.

Elliot, S. (1995), “The Direct Marketing Industry Takes a Look at the Perils of Interactive Technology," The New York Times, 144: C8.

Elliot, Andrew J., and Judith M. Harackiewicz (1996), "Approach and Avoidance Achievement Goals and Intrinsic Motivation: A Mediational Analysis," Journal of Personality and Social Psychology, 70 (3), 461-75.

Ferrari, Joseph R., and John F. Dovidio (2000), "Examining Behavioral Processes in Indecision: Decisional Procrastination and Decisionmaking Style," Journal of Research in Personality, 34 (1), 127-37.

Frost, Randy O., and Deanna L. Shows (1993), "The Nature and Measurement of Compulsive Indecisiveness," Behaviour Research and Therapy, 31 (7), 683-92.

Fujiwara, Okitsugu, Hanijanto Soewandi, and Dayani Dedarage (1997), "An Optimal Ordering and Issuing Policy for a Two-stage Inventory System for Perishable Products," European Journal of Operations Research. 99 (2), 412-24.

Germeijs, Veerle, and Paul De Boeck (2002), "A Measurement Scale for Indecisiveness and Its Relationship to Career Indecision and Other Types of Indecision," European Journal of Psychological Assessment, 18 (2), 113-22.

Greenleaf, Eric A., and Donald R. Lehmann 
(1995). "Reasons for Substantial Delay in Consumer Decision Making," Journal of Consumer Research, 22 (2), 186-99.

Greenwald, A. G., and A. R. Pratkanis (1984), The Self, In R. S. Wyer \& T. K. Srull (Eds.), Handbook of Social Cognition (pp. 129-78), Hillsdale, NJ: Erlbaum.

Hahn, Kyu Hun, Hark Hwang, and Seoung Whan Shinn (2004), “A Return Policy for Distribution Channel Coordination of Perishable Items," European Journal of Operations Research, 152 (3), 770-80.

Hair Jr, Joseph F., William C. Black, Barry J. Babin, and Rolph E. Anderson (2010), Mul-tivariate Data Analysis, 7th Edition, Prentice-Hall International.

Harcar, Talha and Fahri Karakaya (2005), “A Cross-cultural Exploration of Attitudes toward Product Expiration Dates," Psychology \& Marketing, 22 (4), 353-71.

Harriott, Jesse, and Joseph R. Ferrari (1996), "Prevalence of Procrastination Among Samples of Adults," Psychological Reports, 78 (2), 611-16.

Harter, S. (1993), Causes and Consequences of Low Self-esteem in Children and Adolescents, In R. F. Baumeister (Ed.), Selfesteem: The puzzle of low self-regard (pp. 87-116), New York: Plenum Press.

Havlena, William J., and Wayne S. DeSarbo (1990), "On the Measurement of Perceived Consumer Risk," Decision Sciences, 22 (4), 927-39.

170 ASIA MARKETING JOURNAL Vol. 15 №. 02 July 2013
Higgins, E. Tory (1998), "Promotion and Prevention: Regulatory Focus as a Motivational Principle," Advances in Experimental Social Psychology, 30, 1 - 46. , James Shah, and Ronald S. Friedman (1997), “Emotional Responses to Goal Attainment: Strength of Regulatory Focus as Moderator," Journal of Personality and Social Psychology, 72 (3), 515-25. and Orit Tykocinski (1992), "Self-discrepancies and Biographical $\mathrm{Me}^{-}$ mory: Personality and Cognition at the Level of Psychological Situation," Personality and Social Psychology Bulletin, 18 (5), 527-35.

, Christopher J. R. Roney, Ellen Crowe, and Charles Hymes (1994), "Ideal versus Ought Predilections for Approach and Avoidance: Distinct Self-regulatory Systems," Journal of Personality and Social Psychology, 66 (2), 276-86.

Hui, C. Harry (1988), "Measurement of Individualism-Collectivism," Journal of Research in Personality, 22 (1), 17-36.

Jacoby, J., and L. B. Kaplan (1972), The Components of Perceived Risk, in Proceedings of the Third Annual Conference of the Association for Consumer Research, M. Venkatesh, ed. College Park, MD: Association for Consumer Research. 382-93.

Jones, Lawrence. K. (1989), "Measuring a Threedimensional Construct of Career Indecision Among College Students: A Revision of 
the Vocational Decision Scale-The Career

Decision Profile," Journal of Counseling Psychology, 36 (4), 477-86.

Kahneman, Daniel, Jack L. Knetsch, and Richard H. Thaler (1990), "Experimental Tests of the Endowment Effect and the Coase Theorem," Journal of Political Economy, 98 (6), 1325-48.

and (1991). “Anomalies:

The Endowment Effect, Loss Aversion, and Status Quo Bias," Journal of Economic Perspectives, 5 (1), 193-206.

Knetsch, Jack L. (1989), "The Endowment Effect and Evidence of Nonreversible Indifference Curves," American Economic Review, 79 (5), 1277-84.

Knox, B. L., R. L. J. M. van Laack, and P. M. Davidson (2008), "Relationship between Ultimate $\mathrm{pH}$ and Microbial, Chemical, and Physical Characteristics of Vacuum Packaged Pork Loins," Journal of Food Science, 73 (3), M104 - 10.

Li, Michael Z.F. (2001). "Pricing Non-storable Perishable Goods by Using a Purchase Restriction with an Application to Airline Fare Pricing." European Journal of Operations Research, 143 (3), 631-47.

Liberman, Nira, Lorraine Chen Idson, Christopher J. Camacho, and E. Tory Higgins (1999), "Promotion and Prevention Choices between Stability and Change," Journal of Personality and Social Psychology, 77 (6).
$1135-45$.

Lockwood, Penelope, Christian H. Jordan, and Ziva Kunda (2002), "Motivation by Positive or Negative Role Models: Regulatory Focus Determines Who Will Best Inspire Us," Journal of Personality and Social Psychology, 83 (4), 854-64.

Markus, Hazel Rose, and Shinobu Kitayama (1994), “A Collective Fear of the Collective: Implications for Selves and Theories of Selves," Personality and Social Psychology Bulletin, 20 (5), 568-79. and Elissa Wurf (1987).

"The Dynamic Self-concept: A Social Psychological Perspective," Annual Review of Psychology, 38, 299-337.

McCorkle, Denny E. (1990), "The Role of Perceived Risk in Mail Order Catalog Shopping," Journal of Direct Marketing, 4 (4), 26-35. Mela, David J. (1999), "Food Choice and Intake: the Human Factor," Proceedings of the Nutrition Society, 58 (3), 513 - 21.

Mitchell, V.-W. (1998), “A Role for Consumer Risk Perceptions in Grocery Retailing," British Food Journal, 100 (4), 171-83. (1999), "Consumer Perceived Risk: Conceptualizations and Models," European Journal of Marketing, 33 (1/2), 163-95. and M. Greatorex (1993), "Risk Perception and Reduction in the Purchase of Consumer Services," Service Industries Journal, 13 (4), 179-200. 
Mitsostergios K.T. and C.H. Skiadas (1994), "Attitudes and Perceptions of Fresh Pasteurized Milk Consumers: A Qualitative and Quantitative Survey," British Food Journal, 96 (7), 4-10.

Murray, Keith B., and John L. Schlacter (1990), "The Impact Services Versus Goods on Consumer's Assessment of Perceived Risk and Variability," Journal of the Academy of Marketing Science, 18 (1), 51-65.

Peter, J. Paul, and Michael J. Ryan (1976), "An Investigation of Perceived Risk at the Brand Level," Journal of Marketing Research, 13 (2), 184-88.

Rassin, E. (2004), Indecisiveness and Worst Case Scenario Reasoning, In Poster presented at the European Conference of Behavioural and Cognitive Psychotherapy, 11 September 2004, Manchester, UK.

Roselius, Ted (1971), "Consumer Rankings of Risk Reduction Methods," Journal of Marketing, 35 (1), 56-61.

Rozin, Paul, and Hely Tuorila (1993), "Simultaneous and Temporal Contextual Influences on Food Acceptance," Food Quality and Preference, 4 (1-2), 11 - 20.

Shah, James, E. Tory Higgins, and Ronald S. Friedman (1998), "Performance Incentives and Means: How Regulatory Focus Influences Goal Attainment," Journal of Personality and Social Psychology, 74 (2), 285-93.

Shweder, Richard A., and Edmund J. Bourne
(1984), Does the Concept of The Person Vary Cross-Culturally?, In R. A. Shweder \& R. A. LeVine (Eds.), Culture Theory: Essays on Mind, Self, and Emotion (pp. 158-199), Cambridge, England: Cambridge University Press.

Singelis, Theodore M. (1994), "The Measurement of Independent and Interdependent SelfConstruals," Personality and Social PSychology Bulletin, 20 (5), 580-91.

Stone, Robert N., and Kjell Grønhaug (1993), "Perceived Risk: Further Considerations for the Marketing Discipline," European Journal of Marketing, 27 (3), 39-50

Tabachnick, Barbara G., and Linda S. Fidell (1996), Using Multivariate Statistics, Third Edition, New York: Hamper College Publishers.

Tallis, Frank (1997), "The Neuropsychology of Obsessive-compulsive Disorder: A Review and Consideration of Clinical Implications," British Journal of Clinical Psychology, 36 (1), 3-20.

Tesser, Abraham (1986). Some Effects of Selfevaluation Maintenance on Cognition and Action, In R. M. Sorrentino \& E. T. Higgins (Eds.), Handbook of Motivation and Cognition: Foundations of Social Behavior (pp.435-464), New York: Guilford Press.

Thaler, Richard (1980), “Toward a Positive Theory of Consumer Choice," Journal of Economic Behavior and Organization, 1 
(1), 39-60.

Triandis, Harry C. (1989), "The Self and Social

Behavior in Differing Cultural Contexts,"

Psychological Review, 96 (3), 506-20.

Robert Bontempo, Hector

Betancourt, Michael Bond, Kwok Leung,

Abelando Brenes, James Georgas, C. Harry

Hui, Gerardo Martin, Bernadette Setiadi, Jai

B. P. Sinha, Jyoti Verma, Johb Spangenberg,

Hubert Touzard, and Germaine de Montmollin (1986), "The Measurement of Etic aspects of Individualism and Collectivism Across Cultures," Australian Journal of Psychology, 38 (3), 257-67.

Christopher McClusker, and

C. Harry Hui (1990), "Multimethod Probes of Individualism and Collectivisim," Journal of Personality and Social Psychology, 59 (5), 1006-20.

Wang, Zhigang, Yanna Mao, and Fred Gale (2008), "Chinese Consumer Demand for Food Safety Attributes in Milk Products," Food Policy, 33 (1), 27-36.

Wansink, Brian (2005), Marketing Nutrition:

Soy, Functional Foods, Biotechnology, and Obesity. Champaign, IL: Univ. of Illinois Press. and Matthew M. Cheney (2005), "Leveraging FDA Health Claims," Journal of Consumer Affairs, 39 (2), 386-98. and S. B. Park (2002),

"Sensory Suggestiveness and Labeling: Do Soy Labels Bias Taste?," Journal of Sensory Studies, 17 (5), 483-91.

Yamaguchi, S., D. M. Kuhlman, and S. Sugimori (1992), Universality of Personality Correlates and Dimensionality of Person's Collectivistic Tendencies, Paper presented at the center for Korean Studies Colloquium, University of Hawaii, Honolulu.

Yeung, Ruth M.W. and Joe Morris (2001), "Food Safety Risk: Consumer Perception and Purchase Behavior," British Food Journal, 103 (3), 170-86.

Yoo, C.J., K.H. Ahn, and S.W. Park (2011), "A Study of the Influence of Online Wordof-Mouth on the Customer Purchase Intention," Asia Marketing Journal, 13 (3), 209-31.

Codex, http://www.codexalimentarius.org/aboutcodex/en/

Korea Consumer Agency(KCA), http://www. kca.go.kr/

Korea Food \& Drug Administration(KFDA), http://www.kfda.go.kr/index.kfda 